\title{
Failure mechanisms as a method for the assessment of structural damage
}

\author{
I. A. E. de Vent \& G. J. Hobbelman \\ Faculty of Architecture, Delft University of Technology, The Netherlands
}

\begin{abstract}
Many historical buildings show signs of structural damage. For an adequate approach it is necessary to establish the cause of this damage. However, there is insufficient knowledge of how causes and signs of damage cohere. This paper presents an overview of the methodology used in the Ph.D. research project on structural defects in masonry church buildings in The Netherlands. The aim of this project is to gain better insight into the relation between signs of structural damage and their causes. This insight will be attained by defining the underlying damaging processes, including the factors that influence them, and describing these processes systematically in structural failure mechanisms. These mechanisms can then be translated into a diagnostic instrument, which can offer support in the search for the cause of a structural defect - and which could help in avoiding new structural damage in the future.
\end{abstract}

Keywords: structural analysis, failure mechanisms, diagnosis, structural damage, masonry, historical church buildings.

\section{Introduction}

Structural defects can constitute a real danger to a historical building - if no measures are taken, they could even lead to putting it out of use [1].

Nevertheless, many historical masonry buildings do show signs of structural damage: deformations, displacements or crack development, fig. 1. From the response to a questionnaire on damage in church buildings in The Netherlands [2], distributed among various parties involved in the maintenance of these buildings, it has become evident that crack development is a particularly widespread problem. And although in many cases the extent of the damage is still limited, the trustees of these church buildings are well aware of the problems related to structural defects, and they show a clear interest in a better support for 
the assessment of these defects. However, this kind of support is not available yet.

Through the method described in this paper, it will be easier to judge the gravity of a structural defect, and to look for an appropriate solution for it.

\section{Project description}

The primary function of any load bearing structure is to carry the loads which act on the building, and transfer these loads to the subsoil on which it has been built. In applied mechanics, this function is translated into three requirements: structures must have a sufficient amount of strength, stiffness and stability.

When signs of structural defects appear, this indicates that a structure does not (or no longer) come up to these demands; crack development points out a lack of strength, deformations and displacements indicate a lack of stiffness or a lack of stability. The appearance of signs of damage can either mean that the structure or its material has changed, or that the loading conditions on the building are different from what was expected when it was built. In both cases, a large number of reasons could have caused these changes.

For an adequate treatment of structural damage, it is necessary to know its exact cause. Type, shape, location and orientation of the damage can give an indication of the cause of failure, and help in framing a hypothesis, which may then be verified or falsified by specific investigation techniques developed in the past decennia. However, an efficient approach to structural defects is hindered due to the fact that the relation between signs of structural damage and their causes has not been defined unambiguously yet.

From the practice of restoration, there is a demand for a standard method for the determination of the cause of a structural defect. Although much research has been done on historical buildings with structural damage, this research has not yet led to such a standard method. No complete overview of damage-cause relations is available, and the knowledge of the processes leading from cause to damage, and how they can be influenced, has not been developed to the full extent.
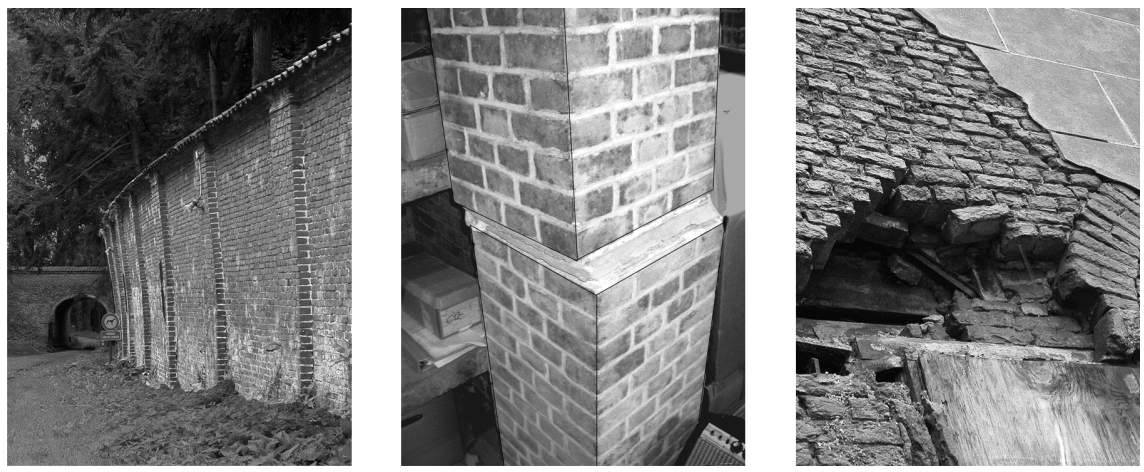

Figure 1: Examples of structural defects: deformation, displacement and crack development. 
Therefore, this research project aims at gaining a better insight in the relation between the signs of structural damage and their causes, and in the underlying processes that form the connection between them. This insight will be attained by means of the definition of structural failure mechanisms, which can be translated in a diagnostic instrument for curative and preventative use in the practice of restoration.

\section{Methodology}

\subsection{Focus on church buildings}

Although the problem of structural defects relates to many historical buildings, this research concentrates on masonry church buildings in The Netherlands. There are three reasons why.

One reason is the topicality of the subject. The increase of building activities nearby or even in church buildings, due to redevelopment of inner-city locations and re-use of unoccupied churches, has led to a current need for better insight in the structural consequences of these activities.

Another reason is related to structural aspects. The typical structural elements, of which church buildings consist, make up most interesting configurations for masonry, such as arches, vaults and domes.

But the main reason lies in the advantages the focus on church buildings has for the methodology of this research. Over 10,000 churches still exist today in The Netherlands [3]. They have been built all over the country, in styles and materials related to the time of construction and to their location. Some of them date back to the tenth century; others were built only recently, fig. 2 .
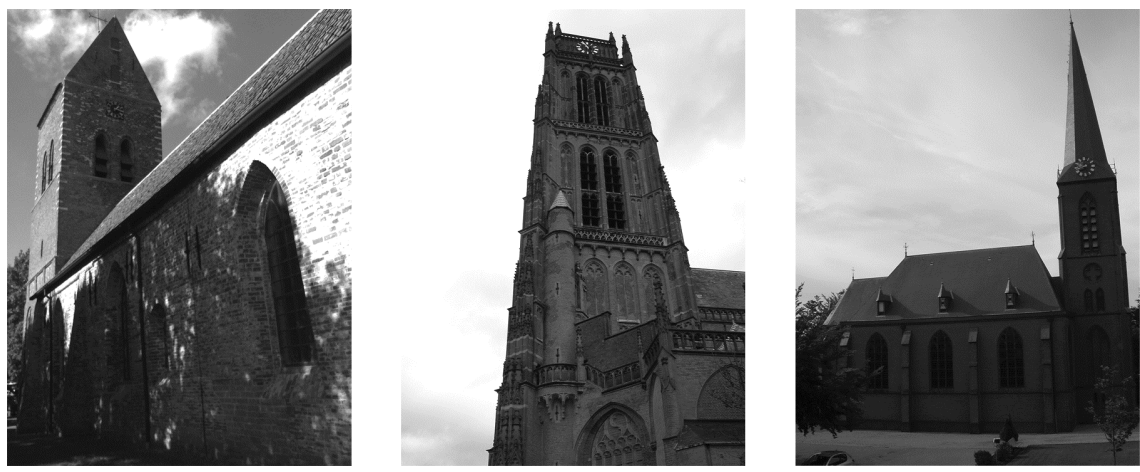

Figure 2: Typical Dutch church buildings: Sint Pancratiuskerk in Godlinze (XII-XIII), Sint Maartenskerk in Zaltbommel (XV) and Petrus- en Pauluskerk in Everdingen (XIX-XX).

These buildings are clearly recognisable as churches; they are linked to the general typology of a church. A typology that is characterised by a consequent 
use and configuration of structural elements, such as the arches, vaults and domes mentioned before.

These constants and variations in the population of church buildings in The Netherlands allow for a comparison between the three variables that are expected to influence the failure processes: context of the building (or environment), structural typology (or geometry) and physical characteristics (or material).

\subsection{Failure mechanisms}

To efficiently establish the cause of a certain sign of structural damage, it is necessary that the courses of various failure processes can be compared. Therefore, this research aims at defining the processes that lead to damage, and subsequently at describing them, systematically and step-by-step, in the format of structural failure mechanisms.

A structural failure mechanism will give, in the first place, an overview of each failure process, by dividing it into four steps: event, impact, effect on the structure and structural damage, fig. 3. An example: an event could be the drainage of an excavation pit. This drainage has an impact on the ground water level, which will lower, causing the soil to settle. The effect on the structure is that the foundation subsides, leaving the wall above it unsupported. This may lead to signs of damage: cracking or leaning of the wall, fig. 4.

\subsection{Factors of influence}

If, and to what extent, a certain process takes place, depends on the presence of the associated factors of influence, related to the environment, the geometry or the materials used in the building, fig. 3. These factors are either prerequisite or contributory to the process. Referring back to the example: in the case of the drainage of an excavation pit, the type of soil (clay soil or sandy soil) will influence the extent of the soil settlement. The type of foundation (shallow or on piles) will influence the effect that the settlement has on the building. And the type of mortar (lime-based or cement-based) will determine the type of damage: deformations or crack development, fig. 4.

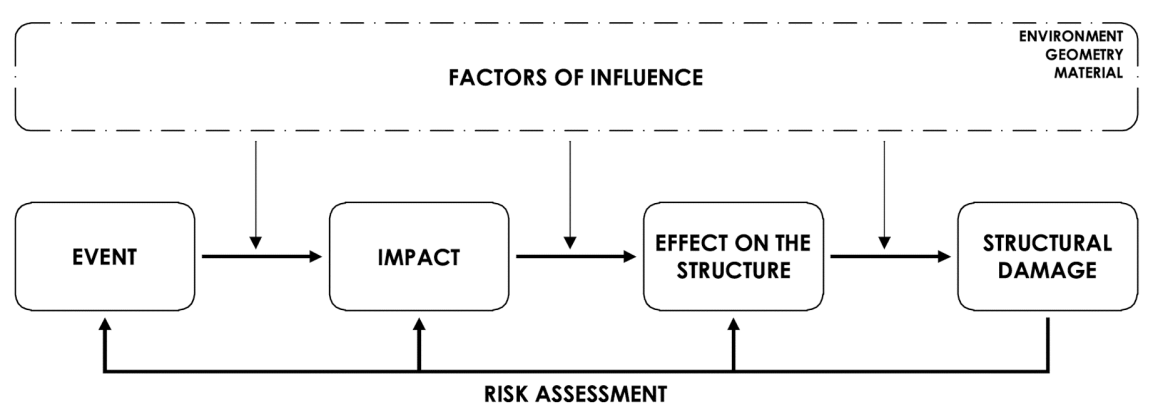

Figure 3: Diagram of a structural failure mechanism. 


\subsection{Approach}

The search for structural failure mechanisms consists of four phases:

- Definition of theoretical failure mechanisms

- First case study research

- Computational modelling and testing

- Verification in second case study research

\subsubsection{Definition of theoretical failure mechanisms}

The structural failure mechanisms will be based on the principles of mechanics. Each loading scenario can be seen as a combination of the four principal loads: axial force (compression or tension), shear force, bending moment and torsional moment. Each principal load can cause certain types of damage. The damage pattern then depends on the failure mode: failure due to a lack of strength, a lack of stiffness or a lack of stability. The failure mode is influenced by the attributes of the structural element on which it is applied. These attributes are either related to the geometry of the structural element, such as the second moment of area I, or to the material of which it is made, such as the tension strength $\sigma_{t}$ and the Young's modulus E.

Thus, the decomposition of the loading scenarios in principal loads makes it possible to define the relation between a loading scenario and a failure pattern, and between a loading scenario and the attributes related to material and geometry.

\subsubsection{First case study research}

To link these theoretical failure mechanisms to the practice of historical buildings, case study research will be used. Approximately twenty-five church buildings with structural defects will be selected on the basis of the response to the questionnaire [2]. These churches will then be analysed. The object of this analysis is threefold.

Firstly, the case study research will contribute to the evaluation of the theoretical mechanisms: are the described loading scenarios plausible for church buildings in The Netherlands, are they complete?

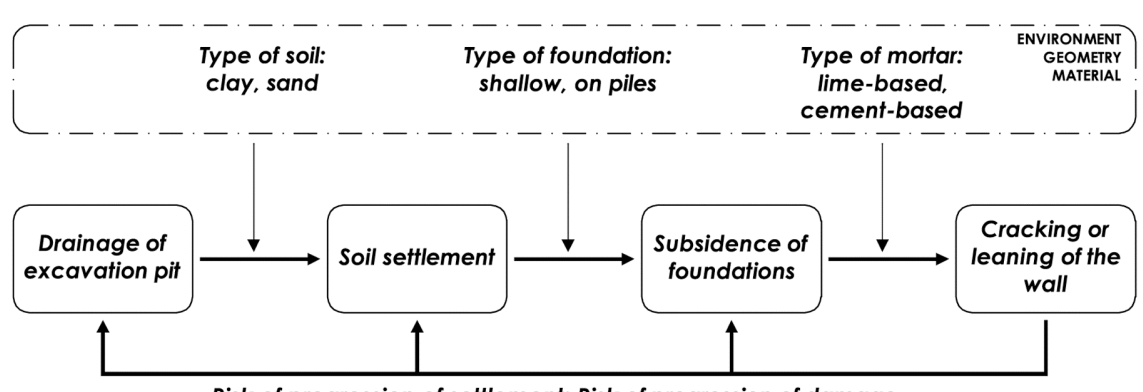

Risk of progression of settlement; Risk of progression of damage

Figure 4: Example of a structural failure mechanism. 
Secondly, the case study research will help in the translation of the theoretical attributes into workable factors of influence, thus type of material instead of $\sigma_{t}$ and $\mathrm{E}$, and thickness of the section instead of I.

Thirdly, the case studies will allow for the determination of the factors of influence related to the environment. These factors affect the way an event nearby a building leads to a certain loading scenario on the building.

In this way, the analysed environmental typologies, geometrical orders and materials of frequent occurrence will determine the probable varieties in the factors of influence.

\subsubsection{Numerical research}

During the third phase, numerical research will be used to examine the influence of each factor on a failure process. For this purpose, the structural elements typical of church buildings in The Netherlands will be modelled in the finite elements program DIANA, fig. 5. These structures will then be loaded under the previously determined loading scenarios.

For each scenario, the factors of influence, defined during the first case study research, will be tested. Related to their position in the diagram of a structural failure mechanism, fig. 4, the influence of the material will be tested on the scale of the structural element, the influence of the geometry on the scale of both the structural element and the building, and the influence of the environment on the scale of the building as a whole.

By comparing the effect of the different factors within one failure process, it might be possible to express the influence of each factor in terms of a percentage.

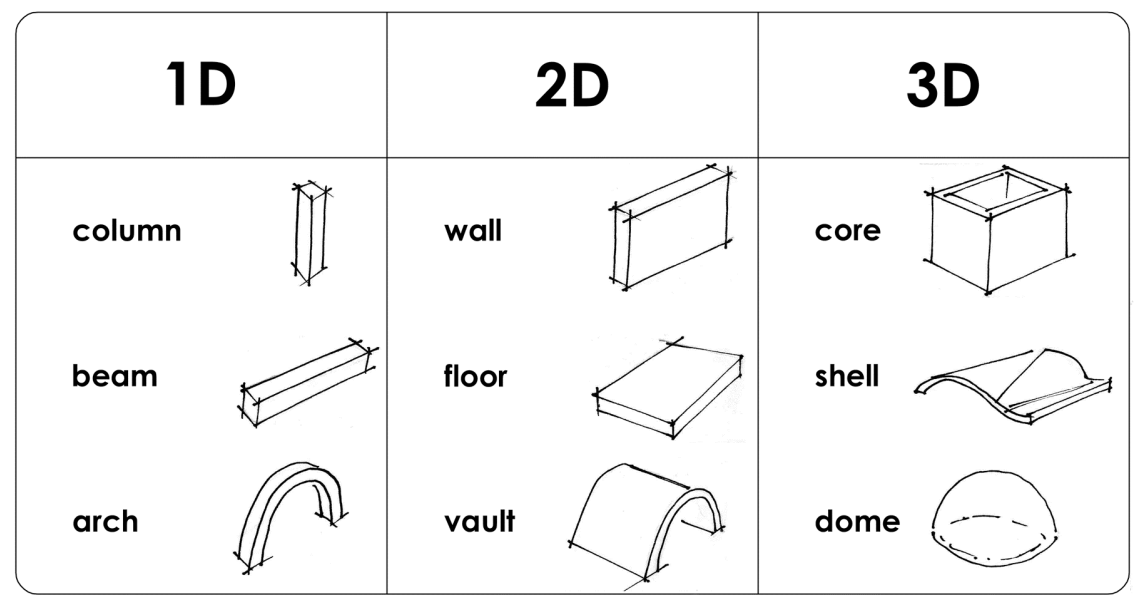

Figure 5: Classification of structural elements. 


\subsubsection{Verification}

The three previous steps have been used to define the failure mechanisms that describe the way loading scenarios can lead to signs of structural damage. In addition, percentages indicate to what extent the factors of influence affect each failure process.

This fourth phase aims at evaluating these failure mechanisms on reliability, completeness and applicability. The method used in this phase is a case study research on a second sample of four church buildings that have already been investigated thoroughly and documented extensively by others. These four cases will be subjected to a renewed investigation, based on the structural failure mechanisms. This investigation process will consist of four steps, fig. 6 .

The first step will be an in-situ visual inspection of the building. With this inspection, both the signs of structural damage and the visible variables of the factors of influence will be detected.

In the second step, this information will be compared to the defined failure mechanisms, and on the basis of this comparison a hypothesis will be framed indicating the most probable cause of the damage.

To verify this hypothesis, more data are needed on the course of the failure process and the presence of factors of influence. Thus, the third step is to draw up an investigation plan, indicating what information should be gathered to be able to check the hypothesis. For the purpose of this verification phase, this information will be extracted from the available documentation on the selected cases. If the data support the hypothesis, the structural defects can be diagnosed, if not, the next most probable hypothesis shall be investigated.

For verification, the last step is to compare the diagnosis based on the structural failure mechanisms to that of the traditional research process. Differences will be analysed to improve the structural failure mechanisms and the proposed investigation process.

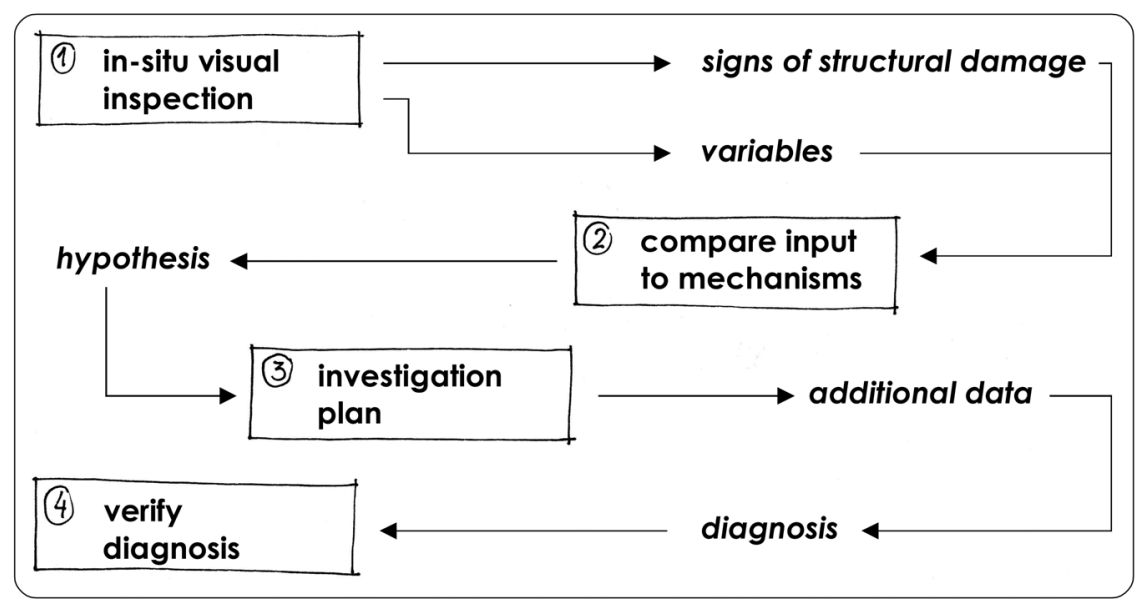

Figure 6: Four steps in the verification phase. 


\section{Implementation}

The overview of failure processes, factors of influence and their relations can constitute the basis of a diagnostic instrument on causes and consequences of structural damage. The use of this diagnostic instrument will have three advantages for the parties involved in the restoration and maintenance of historical buildings with structural defects.

The first advantage is that the use of the diagnostic instrument will structure the investigation process. After starting the digital instrument, the user will be invited to supply general data on the building, which is under examination, and more specific data on the type of damage that has been noticed and the properties and particularities regarding its environment, its geometry and the materials used, fig. 7.

Based on this input, the instrument will compare the variables with the predefined structural failure mechanisms and will list these mechanisms on their probability. This will support the user in the framing of a suitable hypothesis for the cause of damage.

To verify the hypothesis, further investigation on the course of the failure process is needed. The third advantage is that, on the basis of the failure mechanism connected to the hypothesis, the diagnostic instrument will help in selecting an appropriate investigation technique.

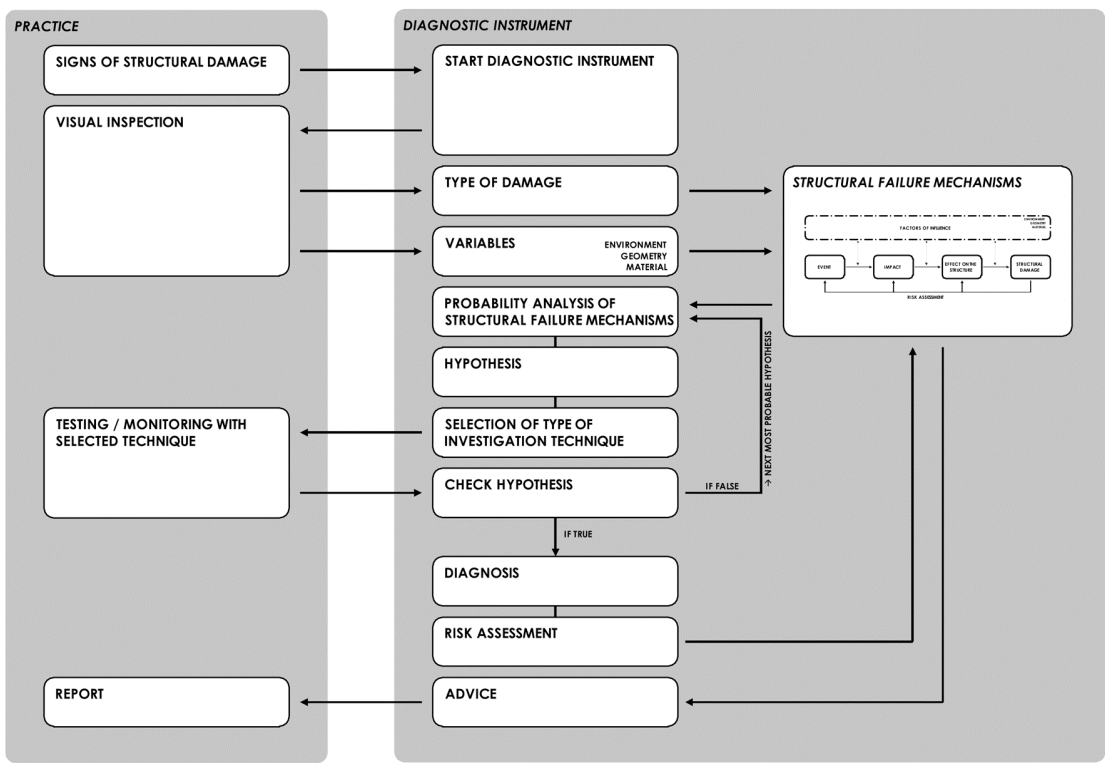

Figure 7: Flow chart of a diagnostic instrument.

The percentages that indicate the influence of each factor allow for an estimation of the chance that a damage pattern is caused by a certain event. But 
in addition to this, it is also possible to estimate the risk that a certain event leads to structural damage. In this way, the diagnostic instrument can be used in two ways in the practice of restoration; curatively, to assess existing damage, and preventatively, to gain insight in the risk that damage could be caused by an intervention in or nearby a building.

\section{Applicability}

This research project focuses, for methodological reasons, on structural defects in masonry church buildings in The Netherlands. Nevertheless, the results of this research are expected to be applicable to a wider variety of buildings.

The failure mechanisms find their basis in the principles of mechanics, which apply to all types of buildings. The results of the first phase of this research will therefore be generally applicable. Concerning the loading scenarios and the factors of influence, from the methods used in the second and third phase it will become clear what their limits are.

Thus, when applying the results of this research to other types of buildings and to other countries, it should be checked if the loading conditions are still representative to a new situation, and if the factors of influence are still applicable and complete.

\section{Conclusions}

The methodology as described in this paper offers an opportunity to gain better insight in the relation between signs of structural damage and their causes.

- By defining the relation between signs of structural damage and their causes by means of describing the underlying processes.

- $\quad$ By defining these failure processes systematically and step-by-step.

- By making use of the principles of mechanics and numerical research, next to case study research.

By following this method, it is possible to give an unambiguous overview of the coherence of causes and signs of structural damage.

This overview can, because it is structured and systematic, be used as the basis of a diagnostic instrument. In this way, the results of this research will allow for an adequate approach to damage in the practice of restoration, and help prevent new damage to occur.

Although this research focuses on structural defects in masonry church buildings in The Netherlands, it is expected that the results will have a wider applicability. The structured description of damaging processes will make it possible to identify readily what the limits of this applicability are.

The results of this research will mainly address applications in the practice of restoration. Besides that, the insight in structural failure processes, and the factors that influence these processes, could help in evaluating and improving the techniques for numerical analysis, so that these techniques have better availability for use in historical buildings. 


\section{Acknowledgements}

The authors wish to thank J. Sonneveld, who has been so kind as to make his database on church buildings in The Netherlands available for the analysis of the population of church buildings and their building periods.

\section{References}

[1] De Vent, I.A.E \& Hobbelman, G.J., Structural analysis of the church of Sint Lambertus in Maastricht. Proceedings of the 5th International Conference on Structural Analysis of Historical Constructions, Possibilities of Numerical and Experimental Techniques, Volume 3, eds. P.B. Lourenço, P. Roca, C. Modena \& S. Agrawal, Macmillan India Ltd.: Delhi, pp. 19571964, 2007.

[2] De Vent, I.A.E., Questionnaire 'Schade aan kerkgebouwen'. Appendix to the Nieuwsbrief 2 of the Vereniging van Beheerders van Monumentale Kerkgebouwen, 2006.

[3] Analysis of church buildings in The Netherlands, based on: Sonneveld, J., Inventarisatie Kerkelijke Gebouwen in Nederland, October 2006. www.hdc.vu.nl/hdc/IKGN. 